\title{
¿PARA QUÉ ENSEÑAMOS LINGÜÍSTICA?
}
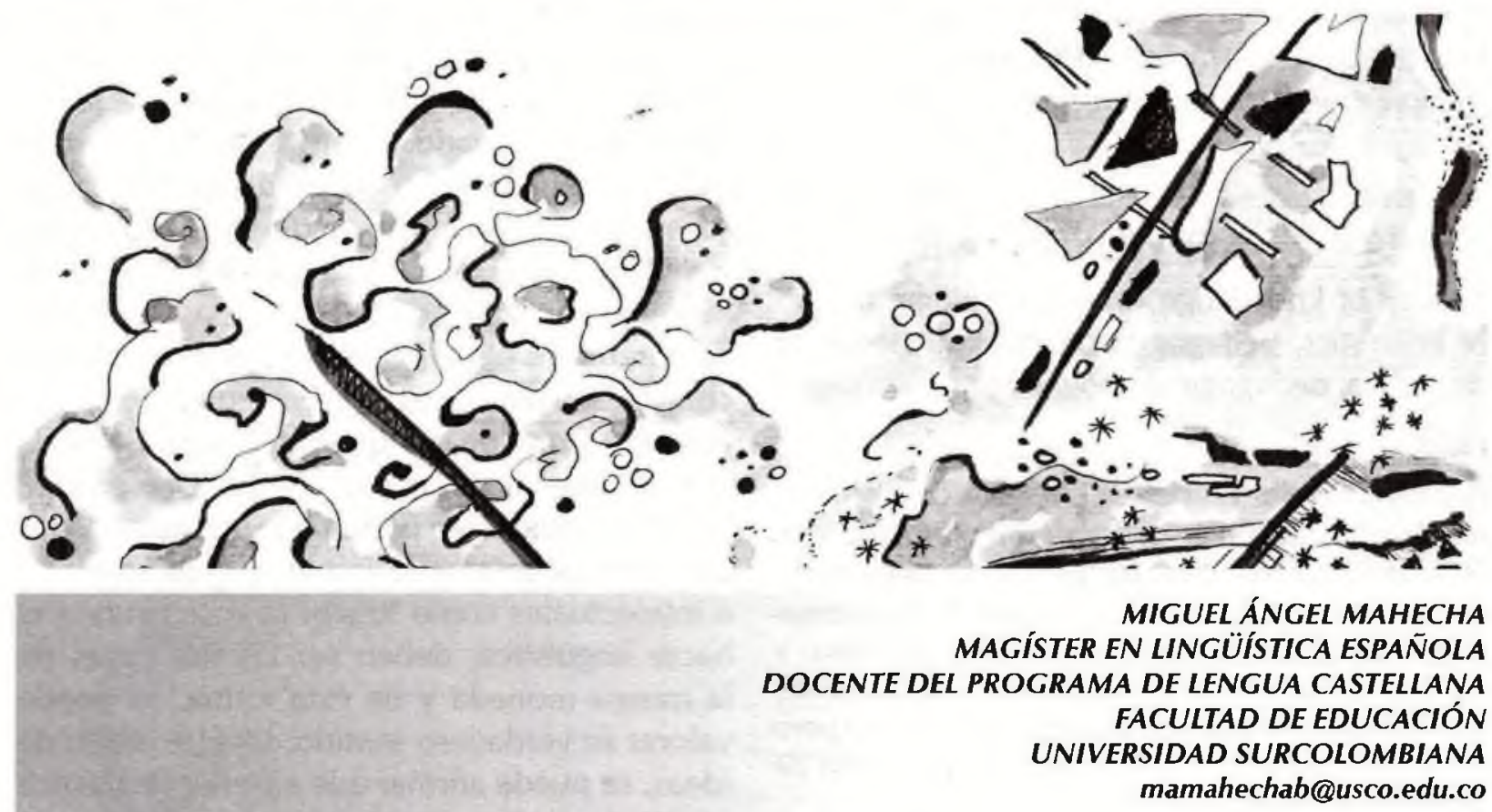

Aं JOSIANE

\section{RESUMEN}

Son dos los objetivos que se persiguen en este escrito. El primero, consiste en destacar que existe una diferencia tanto epistemológica como de reconocimiento social entre el 'hacer' lingüística y 'enseñar' lingüística. El segundo tiene que ver con la capacidad integradora no solo del individuo estudioso sino de la comunidad especializada para construir programas de lingüística adecuados a los referentes sociales de una comunidad académica específica. Para poder acceder a estos dos objetivos es necesario hacer un recorrido por las diversas etapas de la historia de la disciplina (la lingüística) en un medio como el nuestro, para así formular y proyectar propuestas en el área de nuestra disciplina acordes con nuestra realidad social.

\section{PALABRAS CLAVE}

Epistemología, historia de la lingüística, pedagogía, saber disciplinar, saber pedagógico

\section{ABSTRACT}

The present paper has two goals. The first one intends on the desire to highlight the differences between "doing" linguistics and "teaching" linguistics. I will not only be discussing how they differ when it comes to their knowledge theories but also to their social recognition status. The second goal has to do with the ability that exists in an individual as well as in a specialized community to integrate and to build proper syllabus of courses in linguistics that respond to the social background of a specific academic community. In order to achieve these

36 Las ideas que aquí se presentan están sustentadas en dos trabajos anteriores: Hacia una pedagogía de la lingüística (publicado en la revista Paideia Surcolombiana 13) y La lingüistica hoy: su (re)configuración a través de los diferentes objetos de estudio (revista Forma y Función 21). Este artículo es una respuesta 'póstuma' a las inquietudes de un estudiante de filología inglesa de la Universidad Nacional, Giovanni Villada Pulido quien siempre cuestionó la presencia de la teoría lingüística en el aprendizaje de una lengua y reclamó claridad en la comprensión de los conceptos básicos de esta disciplina. 
two objectives, it is necessary to go back in time and take a look at the different periods that this discipline (linguistics) has gone through in history, in an environment like ours. By doing this, it will be possible to formulate new proposals to our discipline according to our social reality.

\section{KEY WORDS}

Theory of knowledge or epistemology, history of linguistics, pedagogy, specific knowledge or discipline, pedagogical knowledge.

"En el estudio de la sociolingüística, de la psicolingüistica y de la lingüistica general, necesitamos algo más que un simple brochazo de lecturas en torno a estos temas, a estas ciencias. La esencia del lenguaje es parte nuestra. Sólo tenemos que asomarnos por la ventana del asombro $y$ vislumbrar ese universo y acceder a él lentamente, con cautela pero con convicción, con asombro pero con curiosidad inaudita. $Y$, con el placer infinito de conocer, de saber."

"Entrar al mundo de la lingüistica es tan maravilloso como innecesario."

Martha Daza, 1995 y 1997.

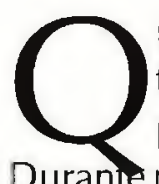
uisiera justificar de entrada tanto el título de este escrito así como los dos pensamientos que le sirven de epígrafe. Durante mucho tiempo se ha asumido, al menos en nuestra realidad, que enseñar lingüística es lo mismo que hacer lingüística. Desde luego no comparto dicha postura pero sí creo necesario aclarar lo siguiente: si bien los procesos de enseñanza/aprendizaje (el saber pedagógico) por un lado, y hacer (de manera científica, i.e. saber disciplinar) lingüística por otro, pueden tomarse de manera independiente, no se ha buscado en nuestro medio colombiano integrar estas dos facetas a la hora de formar profesionales en el campo de reflexión sobre la(s) lengua(s) ${ }^{37}$. Se requiere de un proceso de integración serio, sistemático y contundente para llevar a feliz término dicho objetivo. En las líneas que siguen intentaremos indicar los posibles caminos que se pueden seguir. El título es un llamado a pensar en la actividad de la docencia como resultado de una larga reflexión sobre el contenido epistemológico y metodológico de la disciplina y sus posibles (necesarias) aplicaciones. En este punto, elaboraremos algunas reflexiones relacionadas con los saberes disciplinar y pedagógico Los epígrafes, fruto de la inquietud de una egresada del programa de inglés de la Universidad Nacional, nos hacen pensar que dos actividades tan importantes por sus implicaciones emotivas e intelectuales como lo son la enseñanza y el hacer lingüística, deben ser las dos caras de la misma moneda y de esta forma, se puede valorar su verdadero sentido. En este orden de ideas, se puede afirmar que enseñar lingüística es proponer una serie de mecanismos de pensamiento que nos llevan a comprender los procesos de conceptualización, de creación de modelos teóricos alrededor de lo que se observa en la cotidianidad: en nuestro caso, la comunicación humana a través de las lenguas (i.e. el proceso de significación del mundo). El título de este trabajo no es original del autor; fue tomado de Heles Contreras ${ }^{38}$, profesor chileno que llevó a cabo una interesante reflexión sobre dicha problemática. Sin embargo, en sus planteamientos quedaron muchos puntos sin ser desarrollados (su trabajo era una ponencia que tenía límite de espacio y de tiempo), entre ellos, una reflexión sobre la realidad de la enseñanza de la lingüística en cada país así como la consideración de los problemas epistémicos en la selección de los diferentes objetos de estudio (i.e. perspectivas) de una disciplina como la lingüística. En la primera parte presentaré un breve panorama histórico de la lingüística en Colombia. Seguiré con la reseña

37 Los profesionales a los cuales me refiero son los licenciados en lengua materna o extranjera que se forman en varias universidades del país y reciben una formación lingüística acorde con el perfil que cada programa o departamento ha trazado; lo mismo vale para los lingüistas que se forman en una sola institución: la Universidad Nacional de Colombia sede Bogotá

38 Heles Contreras. 1973. “¿Para qué enseñamos lingüística?”, en Actas de la primera reunión latinoamericana de lingüística y filología. Bogotá, Instituto Caro y Cuervo, pp. 153-159. 
comentada del texto del profesor Contreras y finalizaré con una serie de observaciones sobre la manera como he observado, en calidad de participante (como estudiante y como profesor) el proceso de enseñanza/aprendizaje de la lingüística en la universidad tanto en las carreras de licenciatura en lengua materna e idiomas, teniendo en cuenta las relaciones entre el saber disciplinar y el saber pedagógico.

\section{BREVE PANORAMA HISTÓRICO DE LA LINGÜÍSTICA EN COLOMBIA}

Tomaré como punto de referencia las reflexiones llevadas a cabo por los profesores Fernando Antonio Martínez, Rafael Torres Quintero y Carlos Patiño Rosselli ${ }^{39}$ quienes, hasta donde sé, son los únicos que han elaborado reflexiones en torno a la historia de la lingüística en nuestro país. Dicha historia no puede desligarse ni de la historia lingüística general ni de la problemática sociológica. Como se puede apreciar, el dividir en periodos históricos las diferentes etapas por las que ha atravesado la lingüística como disciplina científica, ayuda a comprender mejor el tipo de tendencias y proyecciones a la hora de proponer (así como de comprender) una teoría científica $^{40}$. Es lo que corresponde al factor extradisciplinar. Presentaré a continuación el panorama propuesto por los autores citados supra.

Rafael Torres Quintero retoma y amplia lo propuesto por Fernando Antonio Martínez en lo concerniente a la división cronológica por periodos de la historia de las ideas lingüísticas en Colombia: (i) Desde los orígenes hasta 1867, (ii) Florecimiento: 1867-1910, (iii) Estancamiento: 1910-1940 y (iv) Renacimiento: 1940-1972 ${ }^{41}$

\section{DESDE LOS ORÍGENES HASTA $1867^{42}$}

En este periodo que se inicia con el descubrimiento de América, ve la luz, entre otras cosas, la Gramática Castellana de Nebrija que va a tener un influjo en los trabajos realizados por los evangelizadores en su actividad con las lenguas indígenas para producir obras tales como gramáticas, diccionarios y catecismos, trabajos que constituían catálogos de datos, estudios de comparación y comprensión de una realidad tan exótica como era la de América y a la postre, la proyección de una teoría del lenguaje. En este periodo de casi 300 años, los estudiosos se centran en el trabajo con las lenguas indígenas con el fin de ir consolidando

39 Fernando Antonio Martínez (s.f.). "Para la historia de los estudios lingüísticos en Colombia", en Apuntes para la historia de la ciencia en Colombia I, Bogotá, Fondo Colombiano de investigaciones científicas 'Francisco José de Caldas', Colciencias, pp. 195-209.

Rafael Torres Quintero. 2000. "La lingüística y la filología hispánicas en Colombia", en Obras, tomo Il: Lingüística y literatura. Bogotá, Instituto Caro y Cuervo, pp. 113-178.

Carlos Patiño Rosselli. 1992. "Perspectiva y prospectiva de la lingüística en Colombia 1991", en Ciencias sociales en Colombia, Bogotá, Colciencias, pp. 273-289.

De igual forma, en algunos apartes de su libro "Política idiomática en Colombia" (2001), Víctor Villa M. presenta datos complementarios sobre las instituciones lingüísticas en Colombia. En la misma línea vale la pena destacar una declaración del profesor Gilberto Forero de la UPTC quien en una entrevista concedida a la revista Glotta (Vol. 2 No 3, Sept.-Dic. 1987, pp. 42-48), menciona un proyecto de investigación sobre la lingüística en Colombia: "Personalmente vengo adelantando una investigación que va a servir como marco de referencia para abrir líneas muy concretas [...] He titulado esta investigación 'Desarrollo y estado actual de la lingüística en Colombia'. Me propongo con este trabajo [...] hacer un análisis de las diversas etapas por las cuales han pasado las distintas corrientes y teorías lingüisticas". No sabemos hasta dónde el profesor Forero llegó a cumplir su objetivo. No obstante, el propósito es loable. Por su parte el profesor Rubén Arboleda, de la Universidad Nacional, presentó una semblanza de la lingüística en Colombia, a propósito de los congresos del área en un periodo comprendido entre 1968 y 2002. La semblanza se publicó en la revista 'Lenguaje' de la Universidad del Valle No 29-30 del 2002, pp. 250-278.

40 Cf. En particular J. Emonds et al. 1976, G. Bergounioux (ed.) 1994, así como F. Newmeyer 1988.

41 Esta es la fecha en que Torres Quintero presenta su trabajo.

42 Para más detalles sobre este periodo recomendamos la lectura del libro de Humberto Triana y Antorveza, Las lenguas indígenas en el Nuevo Reino de Granada, así como el texto de José Manuel Rivas Sacconi, El latín en Colombia. 
un esbozo de lingüística indígena. En efecto, la corona española se dio cuenta de la necesidad de aprovechar las ventajas sociolingüísticas que las lenguas indígenas ofrecían. Si bien es cierto que el mosaico lingüístico era variopinto, se podía llevar a cabo una unificación en términos de procesos sociolingüísticos: lenguas vehiculares, actitudes positivas y negativas, bilingüismo, etc. Hacia 1580, Felipe II presentó una política (con su correspondiente planificación ${ }^{43}$ ) lingüística en donde ordena la implementación de cátedras de lenguas generales (o universales); una de ellas era la lengua chibcha que le abriría camino a la lengua castellana. Igualmente en este periodo, el cultivo de las Humanidades Clásicas ${ }^{44}$ tuvo un lugar especial. En 1513 se establece la primera cátedra de latín en Santa Fe, comenzando así una época de trabajo sistemático en esa lengua; actividad claro está, a cargo de los religiosos. Hubo algunos casos de aplicación del latín en la evangelización de los indígenas; éstos últimos aprendían oraciones religiosas en latín. De igual forma se puede decir que es en este periodo, específicamente entre finales del siglo XVIII y comienzos del XIX en donde el español comienza a desplazar, en el plano académico, el papel preponderante del latín.

\section{FLORECIMIENTO (1867-1910)}

Es un periodo que se caracteriza por el surgimiento de personalidades destacadas en el mundo académico muy a pesar del ambiente adverso en el país ${ }^{45}$ y cuya producción intelectual aparte de ser única en Hispanoamérica, estaba al mismo nivel de los grandes desarrollos de la lingüística europea de su tiempo: Rufino José Cuervo (1844-1911), Ezequiel Uricoechea (1834-1880), Miguel Antonio Caro (1843-1909),
Venancio González Manrique (1836-1889), José Manuel Marroquín (1827-1908), Marco Fidel Suárez (1855-1927), entre otros. Son los cuatro primeros los que a mi modo de ver, acumularon los mayores laureles en su producción intelectual. Del lado de Cuervo tenemos las Apuntaciones críticas sobre el lenguaje bogotano, esta obra es un esbozo de un tratado dialectológico del español, el primero en su género, Notas a la gramática de la lengua castellana de Andrés Bello, el Diccionario de Construcción y Régimen de la lengua castellana, Castellano popular y castellano literario, el Castellano en América: polémica con Juan Valera y en coautoría con Miguel Antonio Caro, escribió la Gramática latina para el uso de los que hablan castellano. Cuervo se constituyó en una figura representativa del mundo académico hispano; conoció a profundidad los procedimientos (marcos teóricos) de la lingüística de su época de donde se puede colegir que era un comparatista que poco a poco se fue centrando en el ámbito románico y que trabajó en la consolidación de una teoría lingüística del español. Por su parte, Ezequiel Uricoechea produjo una obra diversa en los diferentes campos del saber y en cuanto a su producción lingüística se destacan su Gramática, vocabulario, catecismo y confesionario de la lengua chibcha, el Vocabulario Páez-castellano, la traducción y refundición de la gramática árabe del alemán al francés de C.P. Caspari, el Alfabeto Fonético de la lengua castellana y sus valiosas observaciones -enmarcadas en el género epistolar- de las Apuntaciones críticas de Cuervo. Miguel Antonio Caro, eminente filólogo que "habrá de ser restaurador y mantenedor de las humanidades en su tierra y 'uno de los más eminentes humanistas que la raza española ha producido durante el siglo $\mathrm{XIX}^{46}$ centra su producción en el trabajo con el latín, iniciando

43 Para las nociones de 'política y planificación lingüísticas' véase Calvet 1987 y $1993 \mathrm{~b}$.

44 Cf. Rivas Sacconi, 1993.

$45 \mathrm{El}$ profesor Fernando Antonio Martínez, en el estudio preliminar de las obras de Cuervo (Tomo I, 1987) hace una semblanza excelente del ambiente cultural colombiano en dicha época. Por su parte, Rufino José Cuervo nos ilustra la situación de los estudios lingüísticos en ese momento: "Los estudios filológicos eran casi una novedad en mi patria; la literatura estaba poco menos que monopolizada por una escuela que no concebía nada superior a Trueba, Fernán Caballero y otros así, y que miraba de mal ojo, si no ridiculizaba, los estudios clásicos o la aplicación a investigaciones científicas, ajenas de palabras extrañas y curiosidades parroquiales...En los pueblos que hablan castellano la filología más que otros ramos, ha padecido la consecuencia de las fórmulas simplísimas del empirismo." Citado por Torres Quintero, 2000:119.

46 Citado en Rivas Sacconi, 1993:347. 
con la redacción de la Gramática latina citada supra, pasando por el Americanismo en el lenguaje $y$ Del uso y sus relaciones con el lenguaje. Venancio González se distinguió por su afición a los idiomas. Estudió en Estados Unidos e Inglaterra. Junto a Cuervo, elaboró la Muestra de un Diccionario de la lengua castellana en 1871 .

\section{ESTANCAMIENTO (1910-1940)}

Ninguno de los autores citado en el acápite anterior y en especial Rufino José Cuervo dejó discípulos que pudieran continuar su obra. A comienzos del siglo XX los problemas sociales se imponen a cualquier tipo de expresión cultural y científica: Entre 1899 y 1903 tendrá lugar la sangrienta Guerra de los mil días que se convertirá en un obstáculo para desarrollos culturales notables. En noviembre de 1903 Panamá se separa de Colombia. Las pocas actividades en torno al lenguaje giran tan solo alrededor de la Academia de la lengua que solo produce especulaciones lingüísticas pasajeras que no se constituyen en una proyección seria de los postulados lingüísticos en boga. En algunos espacios académicos se trata de mantener lo dicho por los sabios del siglo anterior, pero sin avanzar en la configuración teórica de los objetos de estudio. Según Torres Quintero se mantiene y respeta lo existente, claro está que con un alto nivel de discreción.

\section{RENACIMIENTO (1940 HASTA FINALES DE LOS AÑOS 90)}

Las condiciones sociales en Colombia se van haciendo favorables para un cultivo más sistemático de la cultura. Es por eso que por Decreto gubernamental se crea en 1940 el Ateneo de Altos estudios con el nombre de Rufino José Cuervo para que lleve a cabo serias y ambiciosas actividades lingüísticas. En 1942, el Congreso de Colombia crea (Ley $5^{a}$, agosto 25) el Instituto Caro y Cuervo (ICC) "cuyo fin será continuar el Diccionario de construcción y
Régimen de la Lengua Castellana y preparar la reedición crítica de las Disquisiciones filológicas de Cuervo, y cultivar y difundir los estudios filológicos." A partir de entonces este Instituto se echa al hombro la responsabilidad de llevar a cabo una labor científica en torno a la lingüística y a la cultura colombiana. Si bien la producción intelectual y la labor editorial del Instituto ha sido vasta, hay dos obras de largo aliento que son el producto de la tradición y el esfuerzo científico: El Diccionario de Construcción y Régimen de la lengua castellana (DCR) y el Atlas lingüístico y etnográfico de Colombia (ALEC). Son las figuras del sacerdote Félix Restrepo, Pedro Urbano González de la Calle, Rafael Torres Quintero, Luís Flórez, Fernando Antonio Martínez, José Manuel Rivas Sacconi; Francisco Sánchez Arévalo, Ismael Delgado, Rubén Páez Patiño entre otros, la base sobre la cual el Instituto Caro y Cuervo (ICC) se fue constituyendo y fortaleciendo en su labor de difusión del pensamiento lingüístico colombiano. Las universidades colombianas han desempeñado también un papel importante al lado del ICC. Se abrió un espacio en los planes de estudio para el trabajo (léase consideración) con las diversas corrientes lingüísticas reflejadas en el estudio de las lenguas indígenas (etnolingüística), las lenguas criollas (criollística), la lengua materna (gramática, dialectología, sociolingüística, lexicografía, textolingüística, semiótica, análisis del discurso, etc.), el trabajo con la didáctica de la lengua extranjera y la traducción (lingüística aplicada), con resultados discretos. Según lo especificado por el profesor Patiño Rosselli ${ }^{47}$, las universidades se han convertido en espacios de asimilación y de reproducción de teorías según la moda que se presente. Es más, según este autor, la investigación lingüística en Colombia no constituye un avance en la teoría lingüística general. La investigación consiste en la aplicación de teorías y métodos para verificar hipótesis diversas. Lamenta este autor que no se supere el estado de parroquialismo lingüístico y que junto a la consideración de propuestas teóricas de otras latitudes podamos hacer nuestros propios aportes. Nos hemos limitado a fundar 'asociaciones ${ }^{148}$ y a acumular 
una gran cantidad de saberes sin poder (¿cuál será la razón?) integrarlos. En esta misma dirección apuntaba Luís Eduardo Álvarez ${ }^{49}$ al criticar la actitud maniqueísta de los profesores universitarios. Por su parte, Ambrosio Rabanales (1978) insiste en que la lingüística iberoamericana es el producto de la repercusión de teorías lingüísticas gestadas en Europa y en Estados Unidos ${ }^{50}$. Lo que se puede deducir de lo especificado es que en nuestro medio hay una fuerte tendencia a acumular saberes sin saber qué hacer con ellos dejando de lado la actividad de integración y conceptualización ${ }^{51}$.Claro está que hay un grupo -por cierto bastante restringido- de investigadores que buscan la integración de saberes como es el caso del profesor José Joaquín Montes en el campo de la dialectología ${ }^{52}$ así como a elaborar todo tipo de reflexiones sobre el español de Colombia ${ }^{53}$ o como Jorge Páramo Pomareda quien logro producir un modelo formal de la gramática apoyándose en los argumentos de Tesnière, Hjelmslev y Chomsky. Es tal vez el pionero en la comprensión y el manejo de la lingüística matemática en Colombia. Lo mismo sucede con la propuesta de la profesora Lucía Tobón de Castro ${ }^{54}$. Lastimosamente estos intentos -así como otros tantos- de autonomía, anticolonialismo y antiparroquialismo intelectuales, no han logrado abrir una fisura en el sólido muro de la ortodoxia universitaria. Mientras la universidad colombiana no cambie su manera de pensar, no transforme su misión de una simple visión mercantilista y utilitarista y decida dar el viro hacia un tipo novedoso de 'universidad participativa'55, la lingüística, como un proceso reflexivo que se lleva a cabo allí, seguirá siendo una actividad inútil que se irá alejando cada vez más del ideal planteado en el Principio de endogénesis cultural: "las realidades básicas observables van condicionadas al entorno vital a través del proceso de la socialización, lo cual induce a la creatividad orgánica y respeto por las raíces culturales y por las características específicas del ambiente natural y social de los pueblos." 56

49 Luis Eduardo Álvarez. 1981. "Prólogo para los lingüistas", en El café en la lengua. Armenia, Universidad del Quindío, pp. 19-31.

50 "Creo que éste es el caso, bastante frecuente por desgracia, del trasplante puro y simple, a nuestra realidad iberoamericana, de teorías y métodos y modelos extranjeros que nada o muy poco tienen que ver con esta realidad, vale decir, con nuestra idiosincrasia." (pág. 221). Por su parte, Patrick Charaudeau, en una entrevista concedida a Julio Escamilla y publicada en la revista Lenguaje No 21 (1994), habla de un cierto complejo de inferioridad que los hispanos presentan frente a los estudiosos europeos y norteamericanos. Esa es en parte una razón por la cual no se desarrollan ideas propias. De igual forma, Lucía Tobón (1990:44) hace una afirmación que refleja la situación que refleja la situación de la universidad colombiana: “Consiste en que la creación de conocimiento científico no es propósito nacional, "el país carece de vocación investigativa como soporte de la gestión educativa." (El destacado es mío).

51 Cf. El "Prólogo para los lingüísticas" citado supra.

52 El texto, "Dialectología general e hispanoamericana" tiene tres ediciones: 1982, 1987 y 1995. Este libro tiene su antecedente en un librito publicado en 1970 bajo el título de "Dialectología y geografía lingüística", fruto inicialmente de su trabajo consagrado a la recolección de datos para el ALEC, así como de sus clases en el Seminario Andrés Bello del ICC. Las ideas del profesor Montes se han ido puliendo para precisar diversos tópicos de la lingüística.

53 Cf. El estudio preliminar, a cargo del profesor Rubén Arboleda, del libro sobre José Joaquín Montes, preparado por Ricardo Ramírez y publicado en el 2003: José Joaquín Montes Giraldo. Biografía y Bibliografía. Bogotá, Instituto Caro y Cuervo

54 El profesor Páramo dejó escritos tres capítulos de un Curso de lingüística general en donde se pueden apreciar algunas de sus ideas (Chía 1999). La profesora Lucía Tobón sintetiza sus ideas en un libro titulado, "La lingüística del lenguaje. Estudio en torno a los procesos de significar y comunicar". Bogotá, Universidad Pedagógica Nacional, 2001. Hay segunda edición con dos capítulos más.

$55 \mathrm{Tal}$ como lo propone Fals Borda 2003:24. Claro, dicho modelo no está desconectado del modelo de la universidad investigativa.

56 lbíd. Pág. 20. 


\section{2. ¿PARA QUÉ ENSEÑAMOS LA LINGÜÍSTICA?}

Como lo mencioné supra, este es un tema que fue abordado por el profesor Heles Contreras (en adelante $\mathrm{HC}$ ) hace ya varios años y pretendo hacer en este acápite, una reseña de lo presentado, aportando además, algunos comentarios.

HC plantea una tesis inicial: el lingüista, en su trabajo, cumpleunadoblefunción, lade investigador (unrolexclusivamenteintradisciplinar)yladeprofesor (atendiendo a su carácter de 'anfibio cultural' ${ }^{157}$ ). Si bien es cierto que la actividad lingưística llevada a cabo por algunos estudiosos no estaba relacionada directamente con la vinculación a una universidad -pensemos en el caso del colombiano Rufino José Cuervo- o a un centro especializado, en el siglo XX la creación de institutos de investigación dependientes de una universidad hace que los estudiosos de la lingüística se desempeñen en las esferas de la enseñanza y del trabajo sistemático con su respectivo objeto de estudio. En Colombia, por ejemplo los investigadores que hicieron parte del Instituto Caro y Cuervo llevando a cabo las investigaciones del Atlas Lingüístico y Etnográfico de Colombia (ALEC), del Diccionario de Construcción y Régimen de la Lengua Castellana (DCR), y de la publicación de varios textos especializados en el área de la lingüística, fueron también profesores de universidades, asistentes a Congresos y asesores de instituciones educativas. En la universidad, los profesores tienen como función primordial, dictar clases de un área en particular (saber pedagógico/saber disciplinar), tienen la posibilidad además de hacer investigación específica (saber disciplinar) y proyección social. Son muy escasos los casos en donde un lingüista pueda llevar a cabo sus investigaciones si no es un profesor universitario. Pero tal parece que varios de los profesores de lingüística no se han cuestionado ni por el discurso científico que valida su campo del saber, ni por el discurso pedagógico que ayuda a constituir los procesos de enseñanza/aprendizaje de un conocimiento determinado. Es un ejercicio de docencia pasiva y tradicionalista.

Esto nos lleva entonces a considerar la segunda tesis que es una respuesta a la pregunta ¿qué enseñamos bajo el nombre de lingüística?: Diversas materias. Tanto de introducción como específicas y no hay que olvidar que la variedad de las materias depende de los intereses de los profesores según las condiciones extradisciplinares que los afectan: institución a la cual pertenecen, lugares en donde se formaron (si fue en el país o en el exterior) y teorías que han trabajado. A esto hay que sumarle el público a quien va dirigido el trabajo de enseñanza. En cualquier plan de estudios de una carrera de licenciatura (lengua materna y/o lengua extranjera), o de lingüística, se puede apreciar en los nombres de las asignaturas o cursos, la incidencia que algunos de los profesores han tenido en su conformación porque consideran que determinada escuela, autor o tendencia teórica es la más adecuada para hacer presencia en el plan de estudios, pero pocas veces se encuentra la interconexión de dichos saberes, haciendo del campo disciplinar un espacio amorfo y sin orientación ni aplicación definidos. En muchos casos, la lingüística se asocia exclusivamente con la gramática y no se le explica al estudiante con suficiente claridad la relación (epistemológica) que se establece con otras denominaciones disciplinares como la semiótica, la semántica, la textolingüística, la pragmática, la argumentación y el análisis discursivo, entre otras tantas variantes. A esto hay que sumarle otro aspecto extradisciplinary es el prestigio que mantienen algunos docentes entre sus colegas, pues mientras aquellos detentan, por suerte, un título de doctorado, los colegas que tan sólo llegan a maestría, padecen de un complejo de inferioridad y no confrontan las propuestas, que en muchos casos resultan inadecuadas, de las figuras de mostrar, por no entrar en discusiones que al final, no conducen a ninguna parte ${ }^{58}$. Es por eso que los microdiseños curriculares (llamados también planes o programas de trabajo) evidencian, al menos en lo escrito, 
los temas que obligatoriamente se deben tratar, excluyendo por supuesto aquellos que no se relacionan directamente con ellos. Entre diferentes propuestas, hay un acuerdo implícito y es que los cursos de gramática (entendida como morfosintaxis), de lingüística general, de pragmática y de comunicación son los más comunes cuando se comparan los planes de estudios. A más de esto hay que tener en cuenta a quién va dirigido los cursos. El área de lingüística debe cubrir necesidades de aplicación para estudiantes de terapia del lenguaje (fonética y fonología, psicolingüística, sintaxis), para estudiantes de filosofía (pragmática, argumentación, análisis del discurso, epistemología de la lingüística), para los antropólogos (etnolingüística, sociolingüística, etnografía del habla y de la comunicación). Para los estudiantes de licenciatura en lengua materna y/o extranjera la lingüística es presentada ya sea como teoría lingüística o como lingüística aplicada a la enseñanza de las lenguas (sea materna o extranjera). Son estos últimos, junto a los estudiantes de lingüística tout court los que han desarrollado el espacio propicio para la integración entre el saber disciplinar y el saber pedagógico. Es por eso que el profesor Contreras los toma como punto de referencia. Llegamos pues a la tercera tesis, que responde a la pregunta: ¿Qué esperamos que nuestro estudiante de pedagogía en idiomas sea capaz de hacer como producto de un curso de lingüística?
Debe ser capaz de adquirir una actitud científica frente al lenguaje, lo que implica la eliminación de prejuicios comunes tales como la superioridad intrínseca de una lengua sobre la otra, la complejidad de una lengua, la corrección lingüística (el buen decir) y la primacía de lo escrito sobre lo oral, entre otras tantas. Además, el profesor de idiomas debe comprender la estructura, la función y el funcionamiento del sistema lingüístico, detallando los diferentes planos que lo componen. Debe conocer las implicaciones socioculturales de la lengua, fruto del proceso de representación mental de las comunidades.

Esta tesis, formulada en dichos términos sería ideal si los propósitos coincidieran con los contenidosymétodos deenseñanza/aprendizaje de cada uno de los cursos. No en vano HC plantea un interrogante decisivo: ¿Qué tipo de programa se requiere para cumplir con dichos objetivos? El programa debe ser más práctico que teórico. Debe enfrentarse a los estudiantes con los problemas mismos y proporcionarles las herramientas para su solución, más bien que con las diferentes soluciones planteadas por diversas escuelas lingüísticas. Creemos que nuestros programas de lingüística muchas veces pecan en el mismo sentido que tanto se ha criticado en la enseñanza tradicional de idiomas: se habla mucho sobre lingüística y se maneja poco la lingüística misma. Esta tesis debe abordarse con sumo cuidado pues

58 Sería interesante que los especialistas en la versión del análisis crítico del discurso académico, estudiaran los mecanismos de poder y violencia simbólica que se maneja al interior de una comunidad académica en un programa universitario, pues varios de ellos sin duda alguna son los protagonistas y gestores de este fenómeno. Me parece pertinente citar dos declaraciones del profesor Luis Angel Baena que refleja este tipo de conflicto de poderes, ambas son respuestas a las siguientes preguntas: ¿Cómo define usted la lingüística, qué es la lingüística? y la segunda, ¿Qué opina de la utilización que se hace en el presente de la lingüística? A lo que él responde: "Eso depende con quién esté uno peleando; si a mí me ponen frente a un señor de esos que manejan el análisis del discurso, yo le digo que lingüística no es análisis del discurso. Si me lo pregunta un psicólogo, es cosa diferente. Si me lo pregunta un filósofo, tengo que darle una respuesta distinta, no con apoyo de Austin, Searle y compañía, sino en defensa de una forma de ver el lenguaje no como un conjunto de actos de habla, sino como un conjunto de actos de significación, para poder así superar esa visión recortada que nos metieron a todos en la cabeza [...] El problema es qué entendemos por lingüística. Tenemos que volver al principio: lingüística no es el análisis del discurso primero que todo; mejor que decir eso, que la lingüística no es el análisis del discurso, sería tal vez decir que el análisis del discurso no es lingüística." (Revista Lenguaje número 24, agosto de 1996). Para el caso del programa de lengua castellana, por citar un ejemplo próximo, la comunicación y el intercambio entre los profesores miembros del área de lingüística ha sido casi nulo. Los intereses personales del profesor de más peso y tradición (PhD) no coinciden con los intereses personales de los otros miembros (Magíster). Es más, por más que se ha buscado la oportunidad de encauzar los intereses personales al desarrollo de todo el programa de lengua castellana, los intentos han sido inútiles. Casos semejantes se presentan en otros programas de licenciatura de la Facultad de Educación. 
para el caso de cualquier estudioso que quiera hacer lingüística, el propio trabajo con el saber disciplinar lo puede llevar a dejar de lado el trabajo con el saber pedagógico por considerar que este último no aportaría ningún tipo de complemento al desarrollo conceptual intradisciplinar. Pero si el profesor va a presentar sus resultados investigativos en una conferencia, en una ponencia o en el aula de clase, deberá modificar su discurso para hacerlo accesible no sólo a sus pares sino también a un auditorio que puede ser lego en el asunto o estar constituido por estudiantes novatos. Claro, se puede hacer una integración de dichos saberes, intentando comprender la presente aseveración: "cada disciplina al crear su cuerpo de conocimiento va generando su propia pedagogía." ${ }^{259}$

\section{LA LINGÜÍSTICA EN LA UNIVERSIDAD (PROYECCIONES) ${ }^{60}$}

Complementando lo mencionado en el acápite 1, encontramos que en las universidades colombianas, hay un buen número de estudiosos que se dedica a la acumulación del saber (i.e. el manejo de abundante información, erudición y capacidad de adaptación de modelos extranjeros al medio nacional) ${ }^{61}$ pero cuyo vuelo teórico aún no se consolida. Tenemos cabezas visibles en cada campo: en etnolingüística tenemos a Olga Ardila, María Emilia Montes, Carlos Dupont, Carlos Patiño Rosselli, María Stella González, María Luisa Rodríguez de Montes, María
Trillos, Camilo Robayo, Ximena Pachón, Pedro Marín entre otros; en sociolingüística tenemos a Juan Manuel Gómez, Gilberto Forero, Rafael Areiza, Mireya Cisneros, Genoveva Iriarte, Luís Eduardo Álvarez, Maximiliano Caicedo, Yolanda Rodríguez Cadena; en psicolingüística tenemos a Constanza Moya, Luz Aparo Fajardo, María Cristina Torrado, Silvia Baquero y Angela Camargo; en teoría lingüística y gramática del español contamos con Rubén Arboleda, Lucía Tobón, Tito Nelson Oviedo, Jaime Bernal, Julia Baquero; en dialectología con José Joaquín Montes; en fonética con Álvaro Calderón Rivera, Roberto Perry; en semiótica con Rubén Darío Flórez, Armando Silva; en lexicografía tenemos a Edilberto Cruz Espejo, Nancy Rozo, María Clara Hernández, Ivón Zamora y finalmente en análisis del discurso con Luís Alfonso Ramírez, Neyla Pardo, María Cristina Martínez, Julio Escamilla y Alberto Abouchaar.

Hemos dicho que la lingüística ha tenido desarrollos muy limitados en nuestro medio. No obstante, hay algunas propuestas teóricas que han ido más allá y han intentado estar a tono con los grandes desarrollos de la linguística, en particular con la lingüística cognitiva. Los modelos teóricos construidos por los autores que vamos a mencionar más adelante, han sido conocidos por un sector restringido de estudiosos de la lingüística en Colombia. Cada uno de ellos gestó y desarrolló un modelo en condiciones de aislamiento como sucede habitualmente en nuestro país. Antes de hablar entonces de los

59 Lucía Tobón de Castro, 1993,292. El profesor Jairo Hernando Gómez $(1999,37-41)$ va más allá proponiendo que los investigadores integren los dos saberes. Presenta inicialmente dos interrogantes que acosan a los profesores universitarios: "¿Cuál es el porcentaje de disciplina y cuál el de Pedagogía que debe saber un estudiante para profesor? ¿Qué tanta disciplina (en complejidad y profundidad) debe aprender un estudiante para que después pueda enseñar correctamente esa disciplina?" Y propone entonces: " [...] es claro que el formador de docentes no puede estar guiado sólo por el contenido y/o estructura conceptual de la disciplina en cuyo énfasis se está formando, así como tampoco por los dominios prácticos del profesor. En este sentido, una primera contextualización que el formador de docentes debe efectuar es el análisis y puesta en escena del conocimiento y creencia que el estudiante para profesor tiene acerca de la enseñanza y el aprendizaje de la disciplina que va a enseñar profesionalmente. Reconocer los imaginarios y representaciones de lo que es la práctica pedagógica no sólo debe constituirse en el punto de partida de cualquier proceso de enseñar a enseñar, sino también en un proyecto de investigación que se articule a las dimensiones del saber pedagógico de los contenidos."

60 Las ideas presentadas en el presente acápite fueron desarrolladas con más detalle en el segundo capítulo de mi monografía de maestría: La lingüística hoy: su (re)configuración a través de los diferentes objetos de estudio. Su repercusión en algunas propuestas teóricas colombianas.

61 C. El café en la lengua 
profesores Luís Angel Baena, Lucía Tobón de Castro y Jorge Páramo Pomareda ${ }^{62}$, presentaremos algunas razones a manera de justificación del por qué de su selección: 1) Los tres autores han trabajado con una línea de la lingüística que apunta a la comprensión de una lingüística del lenguaje (de la mente); 2) Estos autores han propuesto modelos teóricos ${ }^{63}$ en donde trabajan lo interno y lo externo en la lengua viendo ésta última como un producto del lenguaje. Para el caso del profesor Baena es el 'modelo de la significación'. Para el profesor Páramo es su reflexión sobre la lingüística general proponiendo el 'modelo formal de gramática general'. Finalmente, para la profesora Lucía Tobón, es la propuesta de la 'lingüística del lenguaje'. Los tres modelos tienen relación con el lenguaje como actividad biológica; 3) Contrario a otros autores más reconocidos socialmente en nuestro medio y que cultivan otras líneas de la lingüística, nuestros autores no se caracterizan por haber publicado mucho en lo tocante a su modelo: De Baena contamos con los artículos publicados en diferentes números de la revista Lenguaje de la Universidad del Valle ${ }^{64}$, del profesor Páramo contamos tan sólo con tres escritos en este campo ${ }^{65}$ y de la profesora Lucía Tobón de Castro contamos con una afortunada sistematización de sus ideas presentadas en los cursos del seminario Andrés Bello y sistematizadas en un libro publicado en el $2001^{66}$; 4) Nuestros autores tuvieron en claro que la lengua es significante, es decir, un sistema que se realiza en estructuras y que la lingüística la ha asumido como objeto en la medida en que no ha tenido acceso directo a la mente. Ellos hacen inferencias sobre la realidad mental de las lenguas a partir de lo que se observa en los textos; incitan a ocuparse del lenguaje como significación; 5) Estos autores se preocuparon por sistematizar una reflexión sobre la teoría lingüística que los llevó a considerar problemas epistemológicos no sólo de la lingüística sino también de otras disciplinas que tocan la problemática de la Facultad del lenguaje; 6) Los tres autores se destacaron como excelentes profesores, tuvieron un reconocimiento por parte de sus estudiantes en cuanto al manejo del discurso pedagógico. Así pues, son un buen ejemplo de integración de saber pedagógico y saber disciplinar.

La manera como los autores trataron y comunicaron sus modelos es el mejor ejemplo que tenemos de reconstrucción conceptual y desarrollo del conocimiento integrando diversos tipos de saberes. Vamos a compartir una observación del profesor Baena que resume el propósito de este acápite e invita a que reconstituyamos tanto como profesores y estudiantes, nuestras maneras de abordar la lingüística a nivel universitario, en especial, a nivel de trabajo en licenciatura en lengua materna: "El estudiante no tiene ni la culpa, ni es responsable, ni al derecho ni al revés de ninguna de las cosas que él es; el estudiante actual es el producto de lo que estamos haciendo o están haciendo los profesores en las facultades de humanidades, en las escuelas de lenguaje. Un estudiante de ahora cree que la lingüística no existe, que lo que existe es el análisis del discurso. Si un señor analista del discurso piensa que la semiología no sirve para nada, eso no es culpa de él porque él no tuvo tiempo de pensar

62 Los profesores Baena y Páramos fallecieron en 1996 y 2001 respectivamente. En la revista Forma y Función 10, el profesor Rubén Arboleda elaboró un obituario del profesor Baena; de igual forma el la revista Ideas y Valores 117, la profesora Laura Almandos Mora hizo lo correspondiente con el profesor Páramo.

63 En este trabajo debe entenderse el modelo teórico' o 'propuesta teórica' como la reflexión sistematizada llevada a cabo por un estudioso a lo largo de su carrera académica, en torno a una manera de considerar un referente, en nuestro caso, el lenguaje. El espacio de la enseñanza, actividad obligada en la universidad, sirve como espacio para la confrontación de las ideas y las posibles adaptaciones que se le pueden hacer al modelo.

64 En el número 24 de dicha revista que se publicó como homenaje al propio Baena, se hizo una selección d aquellos artículos que recogían lo más elaborado de su pensamiento.

65 La lingüistica, la lingüística y el tiempo, el tiempo y las lenguas, y el Curso de lingüística general, manuscrito de tres capítulos.

66 La lingüística del lenguaje. Estudio en torno a los procesos de significar y comunicar. Este documento es un ejemplo de saber disciplinar. Hay un texto especial del saber pedagógico escrito por la autora: Propuesta de un proyecto lingüístico para el estudio del español como lengua propia. 
por su propia cuenta sino que se lo inculcaron en su cabeza[...] yo siempre he pensado que a nivel de la licenciatura, por ejemplo, los cursos de lingüística no deberían nunca gastarse en hacer el recuento del pensamiento de don fulano, ni del uno ni del otro, sino que deberían ser unos cursos organizados de tal modo que el muchacho aprenda a leer lingüística y si aprende a leer lingüística, lo demás ya él lo aprende solo." ${ }^{167}$

La propuesta teórica de Baena va encaminada a intentar explicar fenómenos tales como la adquisición del lenguaje y el desarrollo del conocimiento; la relación entre lo que decimos $y$ lo real; las relaciones entre lenguaje $y$ (pensamiento, conciencia, realidad.); el proceso de significación, etc. Para él, hay que tener en cuenta la significación en la teoría lingüística pues esto nos lleva a deducir los conocimientos presentes en la mente de los hablantes. Esa es una visión que podemos ligar al proceso de cognición, pues el carácter representacional del lenguaje se ve realizado en la organización sistémica de las lenguas haciendo evidente lo lingüístico y lo extralingüístico. Para lograr esto, Baena busca desarrollar un modelo de orden semántico en donde se puede mostrar que la significación es el motor de la constitución del conocimiento. El tiene claro que el objeto de la lingüística no se agota en el sistema y que a medida que se logra reconstituir el objeto, la teoría lingüística llegará a explicar el nexo que existe entre lo que un hablante dice con una intención comunicativa y los objetos de la realidad objetiva. Desde esta perspectiva, el lenguaje no es ya un mero instrumento de comunicación, es más bien el productor de significados (conceptos). Baena insiste en que varias de las orientaciones lingüísticas han obviado este rasgo, y considera que es importante (de)mostrar "el papel que el lenguaje juega en el proceso de constitución de lo humano; su papel en el proceso de la cognición humana de la realidad, su función en el proceso de la constitución de la conciencia individualsocial." (1996,132).

Para el caso del profesor Páramo, él defiende la postura de que el lingüista debe llevar a cabo un análisis detallado de las lenguas para poder comprender los estados de lengua y poder hacer así una serie de abstracciones sobre el lenguaje humano. Este procedimiento nos ayuda a comprender la pregunta básica: ¿Qué ocurre cuando una persona habla y otra escucha? El propone, entre otras cosas, una respuesta: "El hablar humano es una conducta muy compleja, en la cual intervienen procesos fisiológicos, psicológicos y mentales, lo que exige que de él se ocupen varias ciencias especializadas. Entre ellas naturalmente la lingüística (fonética, gramática y lexicografía), cuya importancia en lo relacionado con la enseñanza, la educación, la formación integral y la adquisición de identidad no es en absoluto baladí o demodée." (1999, 30).

Dentro del modelo propuesto por la profesora Tobón de Castro, el lenguaje ocupa un papel especial, o en otros términos, preponderante. Podemos ilustrar su modelo en cinco tesis:

Tesis 1: El lenguaje no es la lengua. Una teoría lingüística coherente debe diferenciar entre la facultad ingénita del ser humano para conceptualizar (lenguaje) y el sistema de signos verbales en donde se refleja dicho proceso (lengua). En segundo lugar, para llevar a cabo la explicitación del proceso de 'cognición en el ser humano hay que determinar los diferentes referentes que participan en dicho proceso: el lenguaje y la lengua están en distintos niveles, se complementan más no se excluyen.

Tesis 2: La lingüística tiene como objeto el lenguaje y por eso constituye una teoría que se ocupa de él.

Tesis 3: La lingüística teórica o general es la ciencia del lenguaje que estudia los fenómenos correspondientes al proceso conceptualizarsignificar que se dan en la mente.

Tesis 4: La mente es una dinámica funcional que no se puede ubicar en la realidad física del cerebro.

Tesis 5: La lingüística debe estudiar la conducta simbólica del ser humano como resultado de la acción cognitiva de la mente sin olvidar la relación que existe entre la 'mente' y el 'cerebro'. 
La consideración de estas tesis (así como de otras tantas) nos deja ver que la propuesta teórica de la profesora Tobón de Castro apunta no solo a invitar a los estudiosos de la lingüística para que la consideren como el estudio del lenguaje como proceso de significación (rasgo que compartía con Baena) sino a constituir una lingüística que dé cuenta del comportamiento simbólico de una persona echando mano de los principios de las lenguas y las ciencias cognitivas, en particular la neurociencia.

Queremos destacar que el trabajo con la lingüística en la universidad y más específicamente cuando se trata de un contexto como lo es la Facultad de Educación, requiere de un ejercicio complejo e integral en donde los espacios del aula de clase, del laboratorio experimental, de las prácticas extramuros, de la asistencia a congresos especializados e incluso de las propias asesorías a estudiantes y por qué no de las charlas de cafetería, vayan constituyendo una configuración discursiva -que podemos llamar, tomando un sintagma muy difundido, 'apropiación y divulgación del conocimiento'- cuyo propósito sea lograr el cultivo y la sistematización de representaciones individuales en el diseño de un tejido cultural. En términos de Baena, cultivar la lingüística -y la universidad es el espacio propicio- es tratar "de dar una explicación al nexo que existe entre lo que decimos con una intención comunicativa, y los objetos, relaciones y eventos de la realidad objetiva, material y social." 68 En una licenciatura de lengua castellana en donde el área de lingüística es uno de los componentes al lado de la teoría literaria y la didáctica, el componente disciplinar (cada uno de los cursos) se puede presentar desde el discurso pedagógico buscando la apropiación de métodos y procedimientos para comprender los diferentes niveles de comprensión y de su respectivo avance. Comprender los conceptos de una disciplina no se logra con el aprendizaje y comparación de definiciones por más sofisticadas que parezcan. Se comprende el concepto cuando se comprende la constitución y articulación del modelo que lo contiene. De esa forma, el saber pedagógico puede considerarse como reflexión alternativa, como mecanismo de resemantización del campo del saber. Esto evitaría que los estudiantes, después de haber pasado por ocho semestres de una carrera, y haber sido discípulos incluso de un doctor en lingüística, hayan olvidado los conocimientos disciplinares básicos para su transmisión. La integración de los saberes disciplinar y pedagógico podría arrojarnos luces para tratar de responder el siguiente reto académico: "Cómo conciliar los puntos de vista sobre el Hombre como individuo particular con los puntos de vista del mismo como expresión de la cultura y como organismo biológico." (Bruner, 1991, 15).

\section{BIBLIOGRAFÍA ${ }^{69}$}

ARBOLEDA, R. (2002). Estudios del lenguaje en Colombia. Los congresos del área: 1968-2002. En revista Lenguaje, 29-30 Cali: Universidad del Valle.

BAENA, L.A. (1996). Revista Lenguaje No 24. Cali: Universidad del Valle.

BERGOUNIOUX, G. (ed.) 1994. Aux origines de la linguistique française. Paris : Agora.

BRUNER， J. (1991). Actos de significado. Más allá de la revolución cognitiva. Madrid: Alianza.

CALVET, L.-J. (1987). La guerre de langues. Paris : Payot.

CALVET, L.-J. (1993b). La Sociolinguistique. Paris : PUF,

EMONDS, J. et al. (1976). Lingüística y Sociedad. Madrid: Siglo XXI Editores.

FALS BORDA, O. (2003). Ciencias Sociales, integración y endogénesis. En Grandes

$681996,92$.

69 Se citan los textos que no fueron referenciados con detalle ni en las notas de pie de página ni en el cuerpo del trabajo. 
Conferencias en la Facultad de Ciencias Humanas No 1. Bogotá: Universidad Nacional.

GOMEZ ESTEBAN, J.H. (1999). Relaciones entre saber pedagógico y saber disciplinar. En Acreditación previa, compromiso institucional. Bogotá: Universidad Distrital.

MOCKUS, A. (1995). Anfibios culturales. En Reforma Académica, Documentos. Bogotá: Universidad Nacional.

NEWMEYER, F. (1985). El primer cuarto de siglo de la gramática transformatoria. Madrid: Alianza.

PARAMO, J. (1982). La lingüística. En Foros interdisciplinarios 2. Bogotá: Universidad de los Andes.

PARAMO, J. (1999). Curso de lingüística general. Documento inédito. Chía.

PATIÑO ROSSELLI, C. (1986). En busca de una lingüística colombiana: El postgrado de la Universidad Nacional. En Glotta, Vol. 1, No 3. Bogotá: Instituto Meyer.

RABANALES, A. (1978). Repercusión de las corrientes lingüísticas contemporáneas en Iberoamérica. Separata del Boletín de Filología, tomo 29. Santiago de Chile: Universidad de Chile.

RIVAS SACCONI, J.M. (1993). El latín en Colombia. Bogotá: Instituto Caro y Cuervo.

TORRES QUINTERO, R. (2000).Obras, tomo II. Lingüística y literatura. Bogotá: Instituto Caro y Cuervo.

TOBON DE CASTRO, L. (1993). Propuesta de un proyecto lingüístico para el estudio del español como lengua propia. En Thesaurus, Boletín del Instituto Caro y Cuervo. Bogotá: Instituto Caro y Cuervo.

TOBON DE CASTRO, L. (2001). La lingüística del lenguaje. Estudios en torno a los procesos de comunicar y significar. Bogotá: Universidad Pedagógica Nacional. 